\title{
The rate of protein degradation in isolated skeletal muscle does not correlate with reduction-oxidation status
}

\author{
Julie M. FAGAN and Alfred L. GOLDBERG \\ Department of Physiology and Biophysics, Harvard Medical School, Boston, MA 02115, U.S.A.
}

(Received 6 August 1984/10 December 1984; accepted 14 January 1985)

\begin{abstract}
It has been suggested that the cytoplasmic reduction-oxidation state correlates with, and may regulate, rates of protein breakdown in skeletal muscle. To test whether an increased lactate/pyruvate ratio is in fact generally associated with low proteolytic rates, this ratio was measured in rat extensor digitorum longus muscles incubated under conditions that rates of protein breakdown. Treatment with the calcium ionophore A23187 caused similar large increases in the lactate/pyruvate ratio at $2 \mu \mathrm{M}$, where proteolysis did not change, and at $20 \mu \mathrm{M}$, where proteolysis was greatly accelerated. Omission of $\mathrm{Ca}^{2+}$ from the medium slowed proteolysis, but decreased the lactate/pyruvate ratio. In muscles incubated at $40^{\circ} \mathrm{C}$, rates of proteolysis were faster, but the lactate/pyruvate ratios were higher than at $37^{\circ} \mathrm{C}$. Thus alterations in the redox status do not necessarily correlate with, and can occur independently of, changes in proteolysis. Furthermore, insulin and inhibitors of lysosomal proteinases decreased proteolysis but, in contrast with previous reports, failed to alter the lactate/pyruvate ratio. In addition, protein breakdown decreased in muscles maintained under tension, although redox state did not change. Thus protein degradation can fall without a concomitant change in the reduction-oxidation state.
\end{abstract}

Changes in the reduction-oxidation state of skeletal muscle have been reported to correlate with alterations in the rate of protein degradation in this tissue (Aoki et al., 1977; Tischler, 1980; Tischler \& Fagan, 1982; Fagan, 1983). Certain experimental manipulations that decrease rates of muscle proteolysis were reported to reduce simultaneously the cytosolic NADH-NAD ${ }^{+}$couple. For example, leucine and $\alpha$-oxoisohexanoate, which decrease protein degradation in muscle (Tischler $e t$ al., 1982), reduced the NAD couple in isolated diaphragm, as indicated by an increase in the ratio of lactate/pyruvate (Tischler \& Fagan, 1982). Furthermore, in various physiological states where the rate of muscle proteolysis is high, the NAD couple in this tissue appeared to be in a more oxidized state, as indicated by a decrease in the lactate/pyruvate ratio. In muscles isolated from young rats, rates of protein degradation were higher, and ratios of lactate/pyruvate were lower, than in muscles from older rats (Fagan, 1983). Similarly, food deprivation and acute diabetes, which increased protein degradation in the extensor digitorum longus muscle, decreased the lactate/ pyruvate ratio. However, on refeeding and with long-term diabetes, muscle proteolysis decreased and the ratio of lactate/pyruvate increased (Fagan, 1983; Fagan \& Tischler, 1983).

These correlations led to the proposal that alterations in the reduction-oxidation status may signal the changes in proteolysis (Aoki et al., 1977; Buse et al., 1980; Tischler \& Fagan, 1982), and that metabolites or hormones which decrease proteolysis do so by causing a reduction of the cytosolic $\mathrm{NADH}-\mathrm{NAD}{ }^{+}$couple (i.e. they increase the ratio of lactate/pyruvate). An alternative interpretation of these correlations would be that changes in rates of proteolysis somehow induce alterations in the NAD couple. It is noteworthy that inhibitors of lysosomal proteinases, which decrease protein degradation in muscle, were reported to cause an oxidation of the NAD/NADP couple in the diaphragm (Tischler, 1980; Tischler \& Fagan, 1982).

It is also proposed that insulin, and perhaps other hormones, influence the rate of protein catabolism in muscle through effects on the cytosolic redox state. Insulin, which decreases proteolysis in many tissues (Minemura et al., 1970; Mortimore \& Mondon, 1970; Hershko et al., 1971; Morgan et al., 1972; Fulks et al., 1975; Long et al., 1984), was reported to increase in diaphragm 
muscle the ratio of malate/pyruvate, which was initially assumed to be an indicator of the NADP couple (Tischler \& Fagan, 1982). However, unlike the lactate/pyruvate ratio, the malate/pyruvate ratio may not be a good indicator of the cytoplasmic redox status, since malate dehydrogenase is not located exclusively in the cytoplasm, and the malate enzyme system may not be in equilibrium (Krebs, 1967). Moreover, in subsequent studies, insulin addition did not consistently increase the lactate/pyruvate ratio nor the glutathione redox couple in soleus and extensor digitorum longus muscles (Fagan, 1983). Also, Aoki et al. (1977) found that insulin infusion into forearm muscles of fasted humans did not significantly change the cytosolic NAD couple, as indicated by the venous ratio of lactate/pyruvate, and actually reduced the mitochondrial NAD couple, as indicated by a rise in the $\beta$-hydroxybutyrate/acetoacetate ratio.

In order to test the generality of the proposed relationship between protein degradation and the reduction-oxidation status, we have measured the tissue lactate/pyruvate ratio under a variety of other conditions known to modulate protein breakdown in isolated rat muscles. Because the conditions tested failed to support previous suggestions that alterations in redox status correlated with changes in proteolysis, we have also reinvestigated the reported effects of insulin and inhibitors of lysosomal proteinases on the redox status of muscle.

\section{Experimental}

Cycloheximide, NADH, NAD ${ }^{+}$and lactate dehydrogenase (Rabbit muscle, type II) were purchased from Sigma Chemical Co., and the calcium ionophore A23187 was purchased from Calbiochem-Behring. Porcine insulin was a gift from Lilly Pharmaceutical Co. (Indianapolis, IN, U.S.A.). The proteinase inhibitors leupeptin and chymostatin were kindly provided by Dr. H. Umezawa, Microbial Chemistry Research Foundation (Tokyo, Japan), and Ep-475 (E-64-C) [L-3-carboxy-trans-2,3-epoxypropyl-leucylamido(3-methyl)-butane] was provided by Dr. K. Hanada of the Taisho Pharmaceutical Co. Ltd. (Saitama, Japan).

Male CD rats (40-50g) were purchased from Charles River Breeding Laboratories. Animals were housed in a temperature- and humiditycontrolled environment with a $12 \mathrm{~h}$ light $/ 12 \mathrm{~h}$ dark cycle for 2-4 days before each experiment. Rats were maintained on Purina laboratory chow and water ad libitum, except where indicated.

Rats were killed by cervical dislocation, and the extensor digitorum longus muscles rapidly excised, blotted and weighed. In some experiments, diaph- ragms were dissected out (Goldberg et al., 1975) and cut into four $23-27 \mathrm{mg}$ sections. After a $30 \mathrm{~min}$ preincubation, muscles were transferred to vials containing $2 \mathrm{ml}$ of fresh Krebs-Henseleit (1932) buffer equilibrated with $\mathrm{O}_{2} / \mathrm{CO}_{2}(19: 1)$. Except where indicated, all buffers contained cycloheximide $(0.5 \mathrm{mM})$, glucose $(5 \mathrm{~mm})$, insulin $(0.1$ unit/ $\mathrm{ml})$, leucine $(0.85 \mathrm{mM})$, isoleucine $(0.5 \mathrm{mM})$ and valine ( $1 \mathrm{mM})$. After $2 \mathrm{~h}$, the tissues were removed, blotted and homogenized in ice-cold $0.2 \mathrm{M}-\mathrm{HClO}_{4}$ $(1.5 \mathrm{ml})$. After centrifugation $(10 \mathrm{~min}$ at $2000 \mathrm{~g}$, $4^{\circ} \mathrm{C}$ ), the supernatant was adjusted to $\mathrm{pH} 5.5-6.5$ by the addition of $2.5 \mathrm{M}-\mathrm{KOH} / 0.1 \mathrm{M}-\mathrm{Pipes} . \mathrm{KClO}_{4}$ was then removed by centrifugation $(10 \mathrm{~min}$ at $2000 \mathrm{~g}$ ). Samples of the incubated medium were treated with $\mathrm{HClO}_{4}$, centrifuged as above and adjusted to $\mathrm{pH} 5.5-6.5$

As a measure of the cytoplasmic reductionoxidation state of muscle, the intracellular ratio of lactate to pyruvate was determined. The lactate contents of both the medium and tissue were assayed spectrophotometrically (Hohorst, 1965). Pyruvate in the medium was also assayed spectrophotometrically, and that in the tissue was determined fluorimetrically (Bucher et al., 1965) on the day of the experiment (owing to the instability of pyruvate). The intracellular ratio of lactate to pyruvate was calculated after correction for the amounts of these metabolites found in the extracellular space. Extracellular space in the diaphragm $(0.325 \mu \mathrm{l} / \mathrm{mg})$ and in the extensor digitorum longus muscle $(0.242 \mu \mathrm{l} / \mathrm{mg})$ was estimated from the [carboxy ${ }^{-14} \mathrm{C}$ ]inulin space (Fagan, 1983).

Protein degradation was estimated from the amount of tyrosine released from muscle protein in the presence of cycloheximide, an inhibitor of protein synthesis (Fulks et al., 1975). Tyrosine released from muscle into the incubation medium was measured fluorimetrically (Waalkes \& Udenfriend, 1957).

Most experiments compared the responses of contralateral extensor digitorum longus muscles or pieces of the same diaphragm muscle, and differences were analysed by the paired Student's $t$ test. In certain experiments, extensor digitorum longus muscles from different animals were compared, and an unpaired Student's $t$ test was employed. Each experiment utilized eight to ten animals of identical age and similar body weights. Results presented in the Tables or text were obtained in two or three independent experiments.

\section{Results}

\section{Effects of $\mathrm{Ca}^{2+}$, muscle tension and temperature}

Previous studies have demonstrated a decrease in protein breakdown in muscle on incubation in $\mathrm{Ca}^{2+}$-free buffer (Sugden, 1980; Lewis et al., 1982; 
Rodemann et al., 1982; Baracos et al., 1985). Accordingly, rates of proteolysis in extensor digitorum longus muscles fell by $17 \%$ (Table 1) when they were incubated in media prepared without added $\mathrm{Ca}^{2+}$. This inhibition of proteolysis was not accompanied by an increase in the lactate/pyruvate ratio (Table 1), as the hypothesis relating muscle proteolysis and redox state would predict (Tischler, 1980; Tischler \& Fagan, 1982). On the contrary, the ratio of lactate to pyruvate decreased by $29 \%$.

When skeletal muscles are treated with ionophore $\mathrm{A} 23187$ to promote $\mathrm{Ca}^{2+}$ influx, rates of proteolysis increase (Kameyama \& Etlinger, 1979; Etlinger et al., 1980; Sugden, 1980; Rodemann et al., 1982). In the presence of $2.5 \mathrm{~mm}-\mathrm{Ca}^{2+}$, the ionophore at $20 \mu \mathrm{M}$ increased protein degradation in the extensor digitorum longus muscle; however, lower concentrations of ionophore $(2 \mu \mathrm{M})$ did not alter rates of proteolysis (Table 2; Etlinger et al., 1980). Nevertheless, the lactate/pyruvate ratio increased to a similar extent $(77-84 \%)$ at the low concentrations of A23187 (Table 2). Thus marked alterations in this ratio can be observed in the absence of any change in proteolysis.

When rat muscles are maintained in vitro at

Table 1. Protein degradation and the reduction-oxidation state in muscle incubated in $\mathrm{Ca}^{2+}$-free medium

Contralateral rat extensor digitorum longus muscles were incubated in K rebs-Henseleit buffer prepared without or with $2.5 \mathrm{~mm}-\mathrm{CaCl}_{2}$. Values are means \pm S.E.M. for eight observations.

\begin{tabular}{lcc}
$\begin{array}{c}\text { Ca } \\
\text { incubation medium }\end{array}$ & $\begin{array}{c}\text { Protein } \\
\text { degradation } \\
\text { (pmol of tyrosine/ } \\
\text { 2h per mg) }\end{array}$ & $\begin{array}{c}\text { Tissue } \\
\text { lactate/ } \\
\text { pyruvate } \\
\text { ratio }\end{array}$ \\
\hline $2.5 \mathrm{~mm}$ & $131 \pm 3$ & $302 \pm 22$ \\
None & $109 \pm 4$ & $213 \pm 22$ \\
Difference (\%) $\ldots$ & -17 & -29 \\
$P \quad \ldots$ & $<0.05$ & $<0.05$
\end{tabular}

approximately their resting length (i.e. under some passive tension), protein breakdown falls by 15 30\% (Goldberg et al., 1974, 1975; Etlinger et al., 1980). As shown in Table 3, this decrease in protein breakdown was not associated with a significant change in the tissue lactate/pyruvate ratio. Protein breakdown has been shown to rise in isolated muscles when the incubation temperature was increased from 37 to $40^{\circ} \mathrm{C}$ (Baracos et al., 1984). In the extensor digitorum longus muscle, protein breakdown was $40 \%$ faster at $40^{\circ} \mathrm{C}$ than at $37^{\circ} \mathrm{C}$ (Table 4). This stimulation of proteolysis was not accompanied by a decrease in the ratio of lactate to pyruvate. Instead, the tissue lactate/pyruvate ratio increased by $97 \%$ in muscles incubated at the higher temperature (Table 4). Thus rates of protein breakdown and cytosolic redox status seem to change independently under these various conditions.

It has also been reported that, in certain pathological states, rates of protein breakdown and glycolysis increase concomitantly (Clark \& Mitch, 1983). However, on incubation in the $\mathrm{Ca}^{2+}$ free buffer, the release of lactate from muscle increased by $25 \%$, as did the combined release of lactate and pyruvate, but protein breakdown slowed. Similarly, passive tension on the muscle increased lactate production 3-fold (from $2.3 \pm 0.4$ to $6.9 \pm 7 \mathrm{nmol} / \mathrm{h}$ per $\mathrm{mg}$ of muscle), whereas proteolysis fell (Table 3). Under the other conditions studied, enhanced glycolysis generally accompanied a rise in protein breakdown. In the presence of low or high concentrations of ionophore A23187, the combined release of lactate and pyruvate increased by about $60 \%$ (from $19 \pm 1$ to $29 \pm 1 \mathrm{nmol} / 2 \mathrm{~h}$ per $\mathrm{mg}$ of muscle), but protein breakdown only increased with the higher concentration of ionophore (Table 2). Also, during incubation at $40^{\circ} \mathrm{C}$, the combined release of lactate and pyruvate increased $79 \%$ above the level seen at $37^{\circ} \mathrm{C}$. Thus, under the various conditions studied here, no consistent relationship was observed

Table 2. Effect of the $\mathrm{Ca}^{2+}$ ionophore A23187 on protein degradation and the reduction-oxidation state in muscle Contralateral rat extensor digitorum longus muscles were incubated in the absence or presence of either $2 \mu \mathrm{M}-(\mathrm{Expt}$. I) or $20 \mu \mathrm{M}$ - (Expt. II) ionophore A23187. Ionophore A23187 was solubilized in dimethyl sulphoxide. All muscles were incubated in media containing $2.5 \mathrm{mM}-\mathrm{Ca}^{2+}$ and $0.1 \%$ dimethyl sulphoxide. Values represent the means \pm S.E.M. for eight observations. Differences were significant at: ${ }^{*} P<0.05 ;{ }^{*} P<0.001$; NS (not significant) $=P>0.05$.

Protein degradation Tissue

Expt. [Ionophore A23187] (pmol of tyrosine/2h per $\mathrm{mg}$ ) lactate/pyruvate ratio

\begin{tabular}{lllcc}
\hline I & None & & $125 \pm 5$ & $137 \pm 13$ \\
& $2 \mu \mathrm{M}$ & $134 \pm 5$ & $242 \pm 13$ \\
& Difference $(\%)$ & $\ldots$ & $\mathrm{NS}$ & $+77^{* *}$ \\
II & None & & $92 \pm 2$ & $98 \pm 14$ \\
& $20 \mu \mathrm{M}$ & $132 \pm 6$ & $181 \pm 13$ \\
& Difference $(\%)$ & $\ldots$ & $+43^{* *}$ & $+84^{*}$
\end{tabular}

Vol. 227 
Table 3. Effect of maintenance of resting length on protein degradation and the reduction-oxidation state in muscle Rat extensor digitorum longus muscles were either pinned to plastic supports at resting length or left unrestrained and incubated for $2 \mathrm{~h}$ after the $30 \mathrm{~min}$ preincubation. Values represent the means \pm S.E.M. for seven to eight observations. Data on the effect of stretch were evaluated with the unpaired Student's $t$ test.

\begin{tabular}{|c|c|c|}
\hline Incubation & $\begin{array}{c}\text { Protein } \\
\text { degradation } \\
\text { (pmol of tyrosine/ } \\
\text { 2h per mg of muscle) }\end{array}$ & $\begin{array}{l}\text { Tissue } \\
\text { lactate/ } \\
\text { pyruvate } \\
\text { ratio }\end{array}$ \\
\hline $\begin{array}{l}\text { Unrestrained } \\
\text { Resting length } \\
\text { Difference }(\%) \\
P \quad \ldots\end{array}$ & $\begin{array}{c}240 \pm 5 \\
196 \pm 3 \\
-18 \\
<0.001\end{array}$ & $\begin{array}{c}184 \pm 36 \\
165 \pm 37 \\
\text { NS }\end{array}$ \\
\hline
\end{tabular}

Table 4. Effect of incubation temperature on protein degradation and the reduction-oxidation state in muscle Contralateral rat extensor digitorum longus muscles were incubated at either 37 or $40^{\circ} \mathrm{C}$. Data are means \pm S.E.M. for eight observations.

\begin{tabular}{|c|c|c|}
\hline $\begin{array}{c}\text { Incubation } \\
\text { temperature }\left({ }^{\circ} \mathrm{C}\right)\end{array}$ & $\begin{array}{c}\text { Protein } \\
\text { degradation } \\
\text { (pmol of tyrosine/ } \\
2 \mathrm{~h} \text { per } \mathrm{mg} \text { ) }\end{array}$ & $\begin{array}{c}\text { Tissue } \\
\text { lactate/ } \\
\text { pyruvate } \\
\text { ratio }\end{array}$ \\
\hline $\begin{array}{l}37 \\
40 \\
\text { Difference }(\%) \\
P \quad \ldots\end{array}$ & $\begin{array}{l}193 \pm 3 \\
272 \pm 10 \\
+40^{*} \\
<0.001\end{array}$ & $\begin{array}{c}176 \pm 29 \\
347 \pm 62 \\
+97^{*} \\
<0.001\end{array}$ \\
\hline
\end{tabular}

between overall rates of proteolysis and rates of glycolysis in muscle, as estimated from the combined release of lactate and pyruvate.

\section{Effects of proteinase inhibitors and insulin on redox status}

Because the findings described above (Tables 14) were not consistent with the reported correlation between redox status and protein breakdown, we reinvestigated some of the observations that led to this proposal. Treatment of muscles with leupeptin and chymostatin, both of which inhibit lysosomal thiol proteinases, decreased proteolysis (Libby \& Goldberg, 1978, 1980) and was reported to cause an oxidation of the NAD couple in diaphragm (Tischler, 1980; Tischler \& Fagan, 1982). These investigators proposed that the inhibition of lysosomal proteinases would lead to an oxidation of the NAD couple if alterations in the reductionoxidation state preceded changes in rates of protein breakdown. However, in the present experiments, we failed to observe any change in the lactate/pyruvate ratio after incubation of the extensor digitorum longus muscle with Ep-475, an inhibitor of lysosomal thiol proteinases (Hanada et al., 1978) and chymostatin, an inhibitor of chymotrypsin-like enzymes and cathepsin B (Aoyaga \& Umezawa, 1975; Libby \& Goldberg, 1980). In accord with previous results, these agents inhibited proteolysis by $24-35 \%$ (Libby \& Goldberg, 1978, 1980; Rodemann et al., 1982), even when protein breakdown in the muscles was suppressed by insulin addition (Table 5).

Because the published correlations had been obtained with the cut diaphragm preparation, we reinvestigated the effects of proteinase inhibitors in that preparation. In quarter diaphragms, proteolysis as well as the lactate/pyruvate ratio tend to be more variable than in the soleus and extensor digitorum longus muscles and to be influenced by the size of the muscle fragment (J. M. Fagan \& M. E. Tischler, unpublished work). In our experiments, protein degradation in quarter diaphragms $(23-27 \mathrm{mg})$ decreased from $0.55 \pm 0.03$ to $0.31 \pm 0.01 \mathrm{nmol} / \mathrm{mg}$ of muscle when incubated with leupeptin $(25 \mu \mathrm{M})$ and Ep-475 $(25 \mu \mathrm{M})$. However, this inhibition of proteolysis was not accompanied by a decrease in the lactate/pyruvate ratio. The reason why we are unable to confirm the previous observation is unclear. In any case, the present experiments indicate that decreasing protein breakdown with proteinase inhibitors does not necessarily cause an oxidation of the NAD couple.

We have also reinvestigated the related suggestion that insulin suppressed proteolysis through changes in the reduction-oxidation state. As expected, addition of insulin to extensor digitorum longus muscle decreased rates of protein degradation. However, that ratio of lactate to pyruvate was unchanged (Table 5). Therefore it is unlikely that insulin acts to decrease proteolysis through changes in the redox status.

It is interesting that insulin decreased proteolysis to the same degree in both the presence or absence of inhibitors of lysosomal proteinases (Table 5). In fact, the inhibition of proteolysis caused by insulin and the proteinase inhibitors appeared to be additive (Table 5), as was also found in perfused heart (Morgan et al., 1980). There is appreciable evidence, in cultured cells and perfused organs, that insulin inhibits proteolysis by an effect on lysosomal function (Wildenthal, 1973; Mortimore et al., 1978; Long et al., 1984); however, these data raise the possibility that insulin may reduce muscle proteolysis by affecting enzymes that are not inhibited by Ep-475 and chymostatin. Although Ep-475 and insulin had additive inhibitory effects, Ep-475 did not inhibit proteolysis further in the muscles under passive tension (results not shown). Thus this effect of stretch, unlike that of insulin, may be explained 
Table 5. Effect of proteinase inhibitors on protein degradation and the reduction-oxidation state in muscle in the presence or absence of insulin

Contralateral extensor digitorum longus muscles from rats fasted for $36 \mathrm{~h}$ were incubated in the presence or absence of Ep-475 (100 $\mu \mathrm{M}$; Expt. I) or chymostatin $(25 \mu \mathrm{M}$; Expt. II). Contralateral muscles from fasted rats were also incubated with insulin $(0.1 \mathrm{unit} / \mathrm{ml})$. Insulin $(1 \mathrm{mg} / \mathrm{ml})$ was solubilized in water at alkaline $\mathrm{pH}$ just before use and chymostatin was solubilized in dimethyl sulphoxide. All muscles were incubated in Krebs-Henseleit buffer containing glucose $(2.5 \mathrm{~mm})$ and cycloheximide $(0.5 \mathrm{~mm})$. Incubation buffer in Expt. II contained dimethyl sulphoxide $(0.1 \%)$. Data represent means \pm S.E.M. for eight to ten muscles. The effects of proteinase inhibitors were tested by the paired Student's $t$ test, where ${ }^{*} P<0.001$. The effects of insulin were tested by the unpaired Student's $t$ test, where ${ }^{* *} P<0.001 ; \mathrm{NS}$ (not significant) $=P>0.05$.

Protein degradation

(pmol of tyrosine/

$2 \mathrm{~h}$ per $\mathrm{mg}$ of muscle)

Tissue lactate/pyruvate ratio

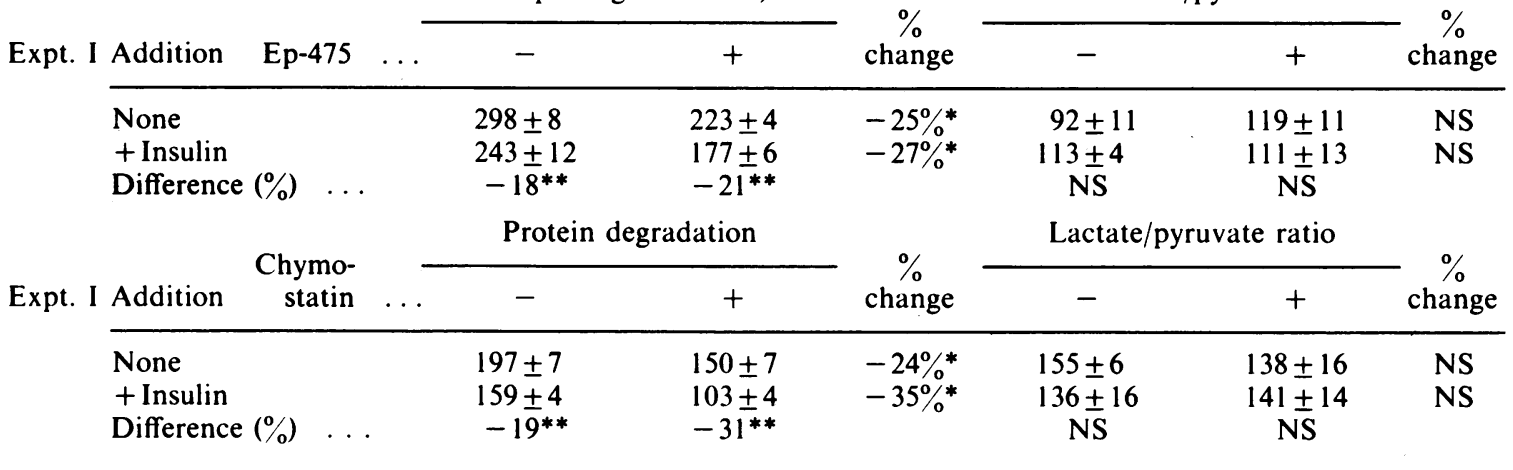

completely by an inhibition of the lysosomal pathway, in accord with other recent observations from this laboratory (V. E. Baracos \& A. L. Goldberg, unpublished work).

\section{Discussion}

The apparent correlation between the reduction-oxidation state of muscle and their rates of protein degradation in a variety of physiological states (Aoki et al., 1977; Tischler, 1980; Tischler \& Fagan, 1982; Fagan, 1983) led to the hypothesis that the cytoplasmic redox status of muscle is a general regulator of protein breakdown (Tischler \& Fagan, 1982). According to this proposal, higher rates of proteolysis should accompany an oxidation of the NAD couple as indicated by a decrease in the lactate/pyruvate ratio. However, we found higher rates of muscle proteolysis with an increase in the lactate/pyruvate ratio (e.g. on incubation with $20 \mu \mathrm{M}$-ionophore A23187 or at $40^{\circ} \mathrm{C}$ ). Conversely, slower rates of protein breakdown would be expected to accompany a reduction of the NAD couple (i.e. an increase in the lactate/pyruvate ratio). However, we found a decrease in the lactate/pyruvate ratio in muscle incubated in $\mathrm{Ca}^{2+}$ free medium and no change in this ratio with passive tension or with inhibitors of lysosomal proteolysis, all of which slowed proteolysis. The latter findings are in contrast with the previous report that leupeptin and chymostatin caused an oxidation of the NAD and NADP couple (Tischler,
1980; Tischler \& Fagan, 1982). Our inability to confirm these observations and our experiments utilizing the $\mathrm{Ca}^{2+}$ ionophore A23187 call into question any simple causal relationship between redox status and proteolysis. For example, ionophore $\mathrm{A} 23187$ at $2 \mu \mathrm{M}$ increased the ratio of lactate to pyruvate without affecting the rate of proteolysis, whereas at $20 \mu \mathrm{M}$ it increased similarly the ratio of lactate to pyruvate but enhanced rates of proteolysis. These results thus show that a reduction in the NAD couple can occur without affecting protein breakdown.

Although these experiments have failed to establish a general causal relationship between redox status and control of proteolysis, or even to confirm certain previous claims, our studies do not necessarily disprove the idea that these two parameters may vary in some co-ordinate fashion in vivo through some indirect mechanism. For example, during the initial few days of starvation or experimentally induced diabetes, muscle protein degradation increased and the NAD couple became more oxidized (Fagan, 1983). This enhancement of proteolysis may be explained by the fall in plasma levels of insulin, but the supply of insulin does not directly influence the cytosolic NAD couple in rat muscle (Table 5) or human muscle (Aoki et al., 1977). However, changes in the levels of other hormones or in the fuels metabolized by the muscle under such conditions may still be responsible for the observed alterations in muscle redox status. 
We thank Ms. Lynette M. Oliphant and Mr. Russell Aminzade for their assistance in the preparation of this manuscript. This work has been supported by research grants from the Muscular Dystrophy Association of America and the U.S. National Institutes of Health. This research was carried out by J. M. F. during the tenure of a Postdoctoral Fellowship from the Muscular Dystrophy Association.

\section{References}

Aoki, T. T., Finley, R. J. \& Cahill, G. F. Jr. (1977) Biochem. Soc. Symp. 43, 17-29

Aoyagi, T. \& Umezawa, H. (1975) Proteases and Biological Control, pp. 429-454, Cold Spring Harbor Laboratory, Cold Spring Harbor, New York

Baracos, V. E., Wilson, E. J. \& Goldberg, A. L. (1984) Am. J. Physiol. 246, C125-C130

Baracos, V. E., Greenberg, R. E. \& Goldberg, A. L. (1985) in Calcium Regulation in Biological Systems (Endo, M. \& Ebashi, S., eds.), Academic Press, Tokyo, in the press

Bucher, T. H., Czok, R., Lamprecht, W. \& Latzko, E. (1965) in Methods of Enzymatic Analysis (Bergmeyer, H. U., ed.), pp. 253-259, Academic Press, New York

Buse, M. G., Weigand, D. A., Peder, D. \& Hedden, M. P. (1980) Metab. Clin Exp. 29, 605-616

Clark, A. S. \& Mitch, W. E. (1983) J. Clin. Invest. 72, 836-845

Etlinger, J. D., Kameyama, T., Toner, K., van der Westhuyzen, D. \& Matsumoto, K. (1980) in Plasticity of Muscle (Pette, D., ed.), pp. 541-557, Walter de Gruyter and Co., New York

Fagan, J. M. (1983) Ph.D. Dissertation, University of Arizona

Fagan, J. M. \& Tischler, M. E. (1983) Fed. Proc. Fed. Am. Soc. Exp. Biol. 42, 339

Fulks, R. M., Li, J. B. \& Goldberg, A. L. (1975) J. Biol. Chem. 250, 290-298

Goldberg, A. L., Jablecki, C. M. \& Li, J. B. (1974) Ann. N.Y. Acad. Sci. 228, 190-201

Goldberg, A. L., Etlinger, J. D., Goldspink, D. F. \& Jablecki, C. (1975) Med. Sci. Sports 7, 258-261

Hanada, K., Tami, M., Yamaguchi, M., Ohmura, S., Sawada, J. \& Tanaka, N. (1978) Agric. Biol. Chem. 42, $523-527$
Hershko, A., Mamont, P., Shields, R. \& Tomkins, G. M. (1971) Nature (London) New Biol. 232, 206-211

Hohorst, H. J. (1965) in Methods of Enzymatic Analysis (Bergmeyer, H. U., ed.), pp. 266-270, Academic Press, New York

Kameyama, T. \& Etlinger, J. D. (1979) Nature (London) 279, 344-346

Krebs, H. A. (1967) Adv. Enzyme Regul. 5, 409-434

Krebs, H. A. \& Henseleit, K. (1932) Hoppe-Seyler's Z. Physiol. Chem. 244, 5713-5723

Lewis, S. E. M., Anderson, P. \& Goldspink, D. F. (1982) Biochem. J. 204, 257-264

Libby, P. \& Goldberg, A. L. (1978) Science 199, 534-536

Libby, P. \& Goldberg, A. L. (1980) Biochem. J. 188, 213 220

Long, W. M., Chua, B. H. L., Munger, B. L. \& Morgan, H. E. (1984) Fed. Proc. Fed. Am. Soc. Exp. Biol. 43, $1295-1300$

Minemura, T., Lacy, W. W. \& Crofford, O. B. (1970) J. Biol. Chem. 245, 3872-3881

Morgan, H. E., Rannels, D. E., Wolpert, E. B., Giger, K. E., Robertson, J. W. \& Jefferson, L. S. (1972) in Insulin Action (Fritz, I. B., ed.), pp. 437-459, Academic Press, New York

Morgan, H. E., Chua, B. \& Beinlich, C. J. (1980) in Degradative Processes in Heart and Skeletal Muscle (Wildenthal, K., ed.), pp. 87-112, Elsevier/NorthHolland Biomedical Press, New York

Mortimore, G. E. \& Mondon, C. E. (1970) J. Biol. Chem. 245, 2375-2383

Mortimore, G. E., Ward, W. F. \& Schworer, C. M. (1978) in Protein Turnover and Lysosome Function (Segal, H. L. \& Doyle, D. J., eds.), pp. 67-87, Academic Press, New York

Rodemann, H.., Waxman, L. \& Goldberg, A. L. (1982) J. Biol. Chem. 257, 8716-8723

Sugden, P. H. (1980) Biochem. J. 190, 593-603

Tischler, M. E. (1980) Biochem. J. 192, 963-966

Tischler, M. E. \& Fagan, J. M. (1982) Arch. Biochem. Biophys. 217, 191-201

Tischler, M. E., Desaultels, M. \& Goldberg, A. L. (1982) J. Biol. Chem. 257, 1613-1621

Waalkes, T. P. \& Udenfriend, S. (1957) J. Lab. Clin. Med. 50, 733-736

Wildenthal, K. (1973) Nature (London) 243, 226-227 